\title{
Erratum: Systemic administration of valproic acid and zonisamide promotes differentiation of induced pluripotent stem cell-derived dopaminergic neurons
}

\author{
Tatsuya Yoshikawa ${ }^{1,2,3}$, Bumpei Samata ${ }^{1,3}$, Aya Ogura ${ }^{1,3}$, Susumu Miyamoto ${ }^{3}$ and Jun Takahashi ${ }^{1,3,4 *}$ \\ 1 Institute for Frontier Medical Sciences, Kyoto University, Kyoto, Japan \\ ${ }^{2}$ Department of Neurosurgery, Mie University Graduate School of Medicine, Tsu, Japan \\ ${ }^{3}$ Department of Neurosurgery, Kyoto University Graduate School of Medicine, Kyoto, Japan \\ ${ }^{4}$ Center for iPS Cell Research and Application, Kyoto University, Kyoto, Japan \\ *Correspondence: jbtaka@frontier.kyoto-u.ac.jp \\ Edited by: \\ Eran Meshorer, The Hebrew University of Jerusalem, Israel
}

\section{A commentary on}

Systemic administration of valproic acid and zonisamide promotes differentiation of induced pluripotent stem cell-derived dopaminergic neurons

by Yoshikawa, T., Samata, B., Ogura, A., Miyamoto, S., and Takahashi, J. (2013). Front. Cell. Neurosci. 7:11. doi: 10.3389/fncel.2013.00011

The Figure 6C in the article is corrected.
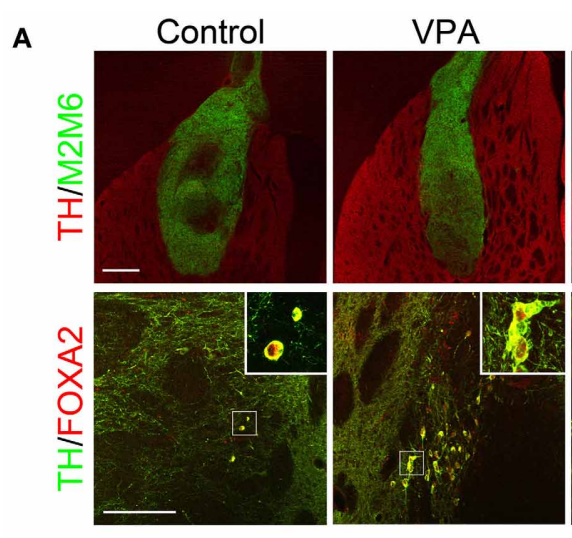

C

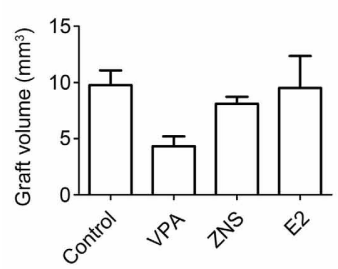

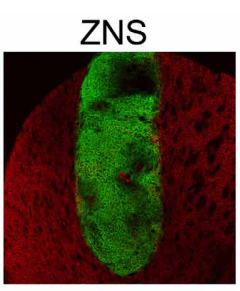
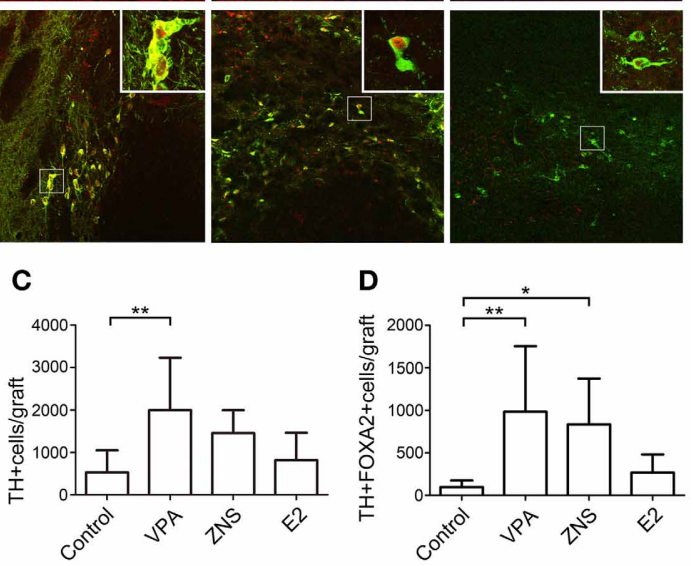

FIGURE 6 | Analyses of iPSC-derived midbrain DA neurons in animals treated withVPA, ZNS, or E2. (A) Representative immunohistologic images of grafts (M2M6; green) containing DA neurons (TH; red), FOXA2 (ventral-midbrain marker; red), and TH (DA neuron marker; green). The scale bar applies to all pictures and represents
$500 \mu \mathrm{m}$ (upper) and $50 \mu \mathrm{m}$ (lower). A comparison between each group for (B) average graft volume, (C) the number of $\mathrm{TH}+$ cells per graft, and (D) the number of TH+FOXA2+ cells(midbrain DA neurons) per graft. The data are presented as the mean $\pm S D .(* P<0.05, * * P<0.01 ; n=8$ control, $n=6$ VPA, ZNS, E2).
Received: 02 July 2013; accepted: 03 July 2013; published online: 22 July 2013. Citation: Yoshikawa T, Samata B, Ogura A, Miyamoto S and Takahashi J (2013) Erratum: Systemic administration of valproic acid and zonisamide promotes differentiation of induced pluripotent stem cell-derived dopaminergic neurons. Front. Cell. Neurosci. 7:116. doi: 10.3389/fncel.2013.00116
Copyright (c) 2013 Yoshikawa, Samata, Ogura, Miyamoto and Takahashi. This is an open-access article distributed under the terms of the Creative Commons Attribution License, which permits use, distribution and reproduction in other forums, provided the original authors and source are credited and subject to any copyright notices concerning any third-party graphics etc. 